\title{
Prevalence of Intestinal Protozoa Infections and Associated Risk Factors Among Preschool Aged Children in Mkuranga District, Tanzania: A Community Based Cross-Sectional Study
}

\section{Ummul-Khair Mustafa}

Dar es Salaam University College of Education

Abdallah Zacharia ( $\sim$ naayz@ymail.com )

Muhimbili University of Health and Allied Sciences School of Public Health and Social Sciences https://orcid.org/0000-0001-9380-6158

\section{Vivian Mushi}

Muhimbili University of Health and Allied Sciences School of Public Health and Social Sciences

\section{Research article}

Keywords: Intestinal protozoa, Preschool aged children, Mkuranga and Tanzania

Posted Date: July 9th, 2020

DOI: https://doi.org/10.21203/rs.3.rs-40609/v1

License: (c) (i) This work is licensed under a Creative Commons Attribution 4.0 International License.

Read Full License 


\section{Abstract}

Background: Intestinal protozoa infections are among the serous public health problems in preschool aged children (PSAC) and can lead to considerable health problems such as growth retardation, anemia, nutrition deficiency, physical weakness and mental health problems. In Tanzania, there is a paucity of data on intestinal protozoa infections though the evidence shows that PSAC can be infected. Therefore, this study aimed to determine the prevalence of intestinal protozoa infections among PSAC and their associated risk factors in Mkuranga district, Tanzania.

Methodology: A community based cross-sectional study was conducted between April and June 2019 to determine the prevalence of intestinal protozoa. A total of 525 stool samples were collected from PSAC and processed using formal-ether concentration method. Risk factors were identified using questionnaire interview conducted among parents/guardians. All participants were randomly selected from two villages (one located in rural and another in suburban settings). Data were entered and analysed by using SPSS version 23.

Results: A total of 20 (3.8\%) out of 525 PSAC were infected with intestinal protozoa (Entamoeba coli or Giardia lamblia). Among the assessed risk factors the following were significantly associated with intestinal protozoa: age of PSAC (AOR $=1.05, p=0.048)$, age group of parents/guardians $\left(A_{0 R} 30-39\right.$ years $/ 50-59$ years $=0.16, p=0.031)$, household population $\left(\mathrm{AOR}_{1-5 / 11_{+}}=0.15, \mathrm{P}=0.018\right.$ and $\mathrm{AOR}_{6-10 / 11_{+}}=$ $0.10, P=0.010)$ and source of water ( $\left(A O R_{\text {tape within household/spring }}=0.004, p=0.015\right),\left(A O R_{\text {protected }}\right.$ well/spring $=0.006, p=0.023),(A O R$ bore hole/spring/spring $=0.006, p=0.012),(A O R$ tape away of home/spring $=$ $0.009, p=0.020)$ and $(A R O$ tape at home/spring $=0.004, p=0.015)$ ).

Conclusion: There was a low prevalence of intestinal protozoa infection among PSAC in the two communities studied. Despite low prevalence of intestinal protozoa, the transmission is present hence the need to initiate control measures. Health education should be provided to parents/guardians of PSAC on protecting water sources, treatment of drinking water and supervision of latrine usage by PSAC and introduction of hand washing facilities are crucial.

\section{Background}

Intestinal protozoa infections are caused by protozoan species and are endemic worldwide especially in developing countries where there is limited access to clean water, poor sanitation and hygiene (1). The intestinal protozoa infections are more prevalent to preschool and school aged children where they contribute to significant morbidity and mortality $(2,3)$. Children are more susceptible to intestinal protozoa infections because of less developed immune system and their behaviors such as playing in fecal contaminated soil, eating with unwashed hands, drinking unsafe water, eating contaminated food and unpeeled fruits (4). Intestinal protozoa infections in children can cause growth retardation, anemia, nutrition deficiency, physical weakness and mental health problems (5). The intestinal protozoa 
infections in children can be asymptomatic or with mild symptoms; protozoa such as Entamoeba histolytica, Giardia and Cryptosporidium parvum can cause severe dysentery and diarrhea (6).

There is significant burden of intestinal protozoa globally. Data collected in 2010 showed that 64 million people suffered from Cryptosporidium species, 104 million people suffered from Entamoeba histolytica and 184 million people suffered from Giardia species leading to more than 30000 deaths (7).

Additionally, 0.43 and $4.0 \%$ of global deaths in children less than five years were due to amoebiasis and cryptosporidiosis respectively (8). Moreover, amoebic colitis account for $9 \%$ of all underfive children deaths in low-income counties (9). In Sub-Saharan Africa the prevalence of intestinal protozoa in children has been reported to range from $16 \%-90 \%$ in different geographical settings with different distribution of protozoan species. Evidence shows that preschool aged children (PSAC) are infected with intestinal protozoa and are capable of maintaining transmission in the community (10).

In Tanzania, little is known about the prevalence of intestinal protozoa in PSAC and their associated risk factors. Also epidemiological data on intestinal protozoa on several parts of Tanzania is lacking. Few studies were conducted to collect information on intestinal protozoa especially in PSAC. A study conducted on school aged children in Pemba (Island Tanzania) showed high prevalence of intestinal protozoa (74.7\%) (11). Another study conducted on diarrhoic underfive children in three hospitals in Dar es Salaam revealed an overall prevalence of $41 \%$ due to Giardia lamblia, Entamoeba histolytica and Cryptosporidium spp infections (12). Therefore this study was conducted to determine the prevalence of intestinal protozoa infections and associated risk factors among PSAC in rural and suburban communities of Mkuranga district, Tanzania.

\section{Methods}

\subsection{Description of the study area}

Mkuranga is one of the six districts of Coast region; the district boarders with Dar es Salaam region, Indian Ocean, Rufiji district and Kisarawe district to the north, east, south and west respectively. According to the population and housing census of 2012, the district has a total population of 222,921 of which males were 108,024 and females were 114,897 (13). Mkuranga was selected because of high prevalence of underfive diarrhea and inadequate water, sanitation and hygiene conditions among many households in the district (14). Additionally, Mkuranga district have both rural and suburban settings providing ideal study site based on our objective. Mwarusembe and Kazole villages were selected from Mwarusembe and Vikindu wards respectively. As per 2012 census, Mwarusembe and Vikindu wards had a population size of 11,706 and 34,762 with an average of 4.2 and 4.5 members per household respectively (13). Mwarusembe village is a rural setting located $70.5 \mathrm{~km}$ south of Dar es Salaam, the country's largest economy city. Kazole village is suburban setting located $27.2 \mathrm{~km}$ south of Dar es Salaam (15).

\subsection{Study design and sampling procedure}


A community based cross-sectional study involving quantitative methods was carried out from April to June 2019. This study was part of the large study that investigated intestinal parasitic infections among PSAC in Mkuranga District. Study participants were PSAC for the prevalence of intestinal protozoa and parents/guardian for assessing risk factors associated with transmission of intestinal protozoa.

Participants were obtained through four stage cluster sampling technique as indicated in Fig. 1. In a household with more than one eligible child, only one was selected using the lottery method.

\subsection{Sample collection and laboratory analysis}

To determine the prevalence of intestinal protozoa; stool samples were collected, processed and examined for presence or absence of intestinal protozoa oocysts, cysts and/or trophozoites. Consented parents were instructed to let the child defecate on the provided clean piece of paper, and use an applicator stick to put a portion of stool into a given clean, dry and wide mouthed stool container. Then store collected sample in a safe place (out of reach of children) to wait for research assistance to pick. Collected samples were immediately transported to Parasitology laboratory at the Muhimbili University of Health and Allied Sciences for examination in the same day of collection. In situations where samples could not be examined in the day of collection, they were preserved in $10 \%$ formalin. A single stool sample was collected per each PSAC. Stool specimens were processed using formol-ether concentration techniques as described in the World Health Organization (WHO) bench aids for the diagnosis of parasitic diseases (16). Examination for the presence of intestinal protozoa oocysts, cysts and/or trophozoites were done using Olympus CX 31 microscope.

\subsection{Questionnaire survey}

A structured questionnaire containing questions adopted and modified from $(17,18)$ supported with observation checklist was used to collect demographic characteristics of participants and possible risk factors associated with protozoa transmission such as water, hygiene and sanitation conditions. All sections of questionnaire were administered to interviewee (mother or other person taking care of a child) by a well trained interviewer.

\subsection{Inclusion and exclusion criteria}

PSAC (1-5 years) living in the study area for the past six months and whose parents or legal guardians signed the written consent were eligible to participate. Those who received anti-intestinal protozoa drugs within one month prior to data collection, children having diarrhea at the time of stool collection, children whom their parents refused to sign a written consent and children aged 5 years but attending primary schools were excluded from the study.

\subsection{Data analysis}

Data collected were cleaned, coded and entered into Statistical Package for Social Sciences version 23 for analysis. The categorical data were summarized using frequency and proportion while mean and standard deviation used for continuous data. Univariate logistic regression was performed to determine association between prevalence of intestinal protozoa and socio-economic, water, hygiene and sanitation 
variables. P-value less than 0.05 were considered statistically significant. Variables shown to have statistical significant association during univariate logistic regression analysis were subjected to multivariate logistic regression test.

\subsection{Ethical considerations}

Ethical clearance was sought from the Muhimbili University of Health and Allied Sciences Ethical Review Board. Permission was obtained at all administrative units involved in this study, from the regional level to the hamlet level where this study was conducted. A written consent was requested from parent or legal guardian of each participant. At the end of the study, a brief report was prepared and sent to the District health officers so that infected children will receive treatment.

\section{Results}

A total of 525 households from the two selected villages were surveyed, each household provided one PSAC with the parent/guardian. The mean age of PSAC was $36.7( \pm 14.3)$ months ranged from 12 to 60 months with the majority (76.8\%) of PSAC participants belonged to the age group 36-60 months. Female PSAC participants were more than half (52.4\%) of all participants. The mean age of parents/guardians was $30.8( \pm 9.1)$ years ranged between 16 to 70 years. Age group 20-29 years contributed high number (44.4\%) of parents/guardians compared to other four groups. Occupations of the interviewed parents/guardians descend in the following order: house wives, self-employed, peasant and private or public employee. Sixty three percent of all parents/guardians attained primary school education level and $19.6 \%$ lacked any kind of formal education (Table 1 ).

The prevalence of intestinal protozoa infection was 20 (3.8\%) in which two species were identified. The two species were Entamoeba coli (2.3\%) and Giardia lamblia (1.5\%). The prevalence was $5.0 \%$ among children in age group 36-60 months with no case in age group 12-24 months. Females were more infected than males with prevalence of $4.7 \%$ and $2.8 \%$ respectively. However, none of the children was found co-infected with the two intestinal protozoa species. The prevalence of intestinal protozoa was high in PSAC raised by parents/guardians aged 50-59 years, employed, with at least secondary school education level and economically good. The high prevalence was also found in children living in households with high number of household members (11+), households without latrines and households without hand washing facilities. One out of 2 PSAC whose parents/guardians reported that they use spring water were infected with Giardia lamblia (Table 1). All infected PSAC were from households with easy access of water, do not treat drinking water and without hand washing facilities after toilet. 
Table 1

presents social-demographic characteristics of study participants and assessed risk factors

\section{Characteristic}

Age groups of PSAC

Sex of PSAC

Study settings

Age groups of parents/guardians

Occupation of parents/guardians

Economic status of parents

Education level of parents/guardians
Categories

12-35 months

36-60 months

Female

Male

Rural

Suburban

$\leq 19$ years

20-29 years

$30-39$ years

40-49 years

50-59 years

Public or private

employee

Self- employee

Peasant

House wife

Weak

Good

Never attended school

Primary education

Secondary education

Tertiary education

$11+$

6-10

$1-5$

Difficult
No of

PSAC

122

403

275

250

254

271

36

233

168

66

22

29

158

96

242

195

330

103

332

67

23

13

194

318

32
No of Infected PSAC

(\%)

$0(0.0)$

$20(5.0)$

$13(4.7)$

7 (2.8)

9 (3.5)

$11(4.1)$

$0(0.0)$

10 (4.3)

4 (2.4)

$3(4.5)$

3 (13.6)

2 (6.9)

$6(3.8)$

3 (3.1)

9 (3.7)

5 (2.6)

15 (4.5)

3 (2.9)

12 (3.6)

4 (6.0)

$1(4.3)$

$3(23.1)$

$5(2.6)$

$12(3.8)$

Water availability

Note: $\mathrm{PSAC}=$ preschool aged children 


\begin{tabular}{|c|c|c|c|}
\hline Characteristic & Categories & $\begin{array}{l}\text { No of } \\
\text { PSAC }\end{array}$ & $\begin{array}{l}\text { No of Infected PSAC } \\
\text { (\%) }\end{array}$ \\
\hline & Easy & 493 & $20(4.1)$ \\
\hline \multirow{6}{*}{$\begin{array}{l}\text { Source of water for domestic } \\
\text { activities }\end{array}$} & Spring & 2 & $1(50.0)$ \\
\hline & Unprotected well & 24 & $0(0.0)$ \\
\hline & Protected well & 27 & $1(3.7)$ \\
\hline & Tube well or bore hole & 207 & $8(3.9)$ \\
\hline & Tape away of home & 224 & $9(4.0)$ \\
\hline & Tape at home & 41 & $1(2.4)$ \\
\hline \multirow[t]{2}{*}{ Drinking water treatment } & No & 28 & $1(3.6)$ \\
\hline & Yes & 497 & $19(3.8)$ \\
\hline \multirow[t]{2}{*}{ Hand washing facility } & Present & 7 & $0(0.0)$ \\
\hline & Absent & 518 & $20(3.9)$ \\
\hline \multirow[t]{2}{*}{ Nails of PSAC } & Untrimmed & 87 & $2(2.3)$ \\
\hline & Trimmed & 458 & $18(3.9)$ \\
\hline \multirow[t]{2}{*}{ Latrine availability } & Not available & 14 & $2(14.2)$ \\
\hline & Available & 493 & $18(3.7)$ \\
\hline \multirow[t]{2}{*}{ Latrine use by PSAC } & Use latrine & 245 & $17(6.9)$ \\
\hline & Not use latrine & 280 & $3(1.1)$ \\
\hline
\end{tabular}

Table 2 summarizes the results of univariate and multivariate logistic regression tests. The test indicated statistically significant association between protozoa prevalence and age of preschool children, age group of parents/guardians, households' population and latrine use by PSAC $(p<0.05)$. When these factors were analysed using multivariate logistic regression, all were significantly associated with intestinal protozoa prevalence $(p<0.05)$ except for the latrine use. 
Table 2

Association between intestinal protozoa infection and risk factors (socioeconomic, behavioral, water, hygiene and sanitations)

\begin{tabular}{|c|c|c|c|c|c|}
\hline \multirow[t]{2}{*}{ Variable } & \multirow[t]{2}{*}{ Categories } & \multicolumn{2}{|c|}{$\begin{array}{l}\text { Univariate logistic } \\
\text { regression }\end{array}$} & \multicolumn{2}{|c|}{$\begin{array}{l}\text { Multivariate logistic } \\
\text { regression }\end{array}$} \\
\hline & & OR (95\% Cl) & $\begin{array}{l}\mathrm{P}- \\
\text { value }\end{array}$ & $\begin{array}{l}\mathrm{AOR}(95 \% \\
\mathrm{Cl})\end{array}$ & $\begin{array}{l}P \text { - } \\
\text { value }\end{array}$ \\
\hline Age (PSAC) & Age in months & $\begin{array}{l}1.09(1.04- \\
1.14)\end{array}$ & $<.001$ & $\begin{array}{l}1.05(1.00- \\
1.13)\end{array}$ & 0.048 \\
\hline \multirow[t]{2}{*}{ Sex of PSAC } & Male & 1 & & NA & NA \\
\hline & Female & $\begin{array}{l}1.72(0.68- \\
4.39)\end{array}$ & 0.254 & & \\
\hline \multirow[t]{2}{*}{ Study settings } & Rural & 1 & & NA & NA \\
\hline & Suburban & $\begin{array}{l}0.87(0.35- \\
2.13)\end{array}$ & 0.758 & & \\
\hline \multirow{5}{*}{$\begin{array}{l}\text { Age groups of parents or } \\
\text { guardians }\end{array}$} & $50-59$ years & 1 & & 1 & \\
\hline & $40-49$ years & $\begin{array}{l}0.30(0.06- \\
1.62)\end{array}$ & 0.162 & $\begin{array}{l}0.33(0.05- \\
2.02)\end{array}$ & 0.229 \\
\hline & $30-39$ years & $\begin{array}{l}0.15(0.03- \\
0.74)\end{array}$ & 0.020 & $\begin{array}{l}0.16(0.03- \\
0.85)\end{array}$ & 0.031 \\
\hline & $20-29$ years & $\begin{array}{l}0.28(0.07- \\
1.12)\end{array}$ & 0.072 & $\begin{array}{l}0.33(0.07- \\
1.47)\end{array}$ & 0.146 \\
\hline & $\leq 19$ years & 0.000 & 0.998 & 0.000 & 0.998 \\
\hline \multirow{4}{*}{$\begin{array}{l}\text { Occupation of parents or } \\
\text { guardians }\end{array}$} & House wife & 1 & & NA & NA \\
\hline & Self-employee & $\begin{array}{l}1.02(0.36- \\
2.93)\end{array}$ & 0.968 & & \\
\hline & Peasant & $\begin{array}{l}0.84(0.22- \\
3.15)\end{array}$ & 0.790 & & \\
\hline & $\begin{array}{l}\text { Public/private } \\
\text { employee }\end{array}$ & $\begin{array}{l}1.92(0.39- \\
9.34)\end{array}$ & 0.420 & & \\
\hline \multirow[t]{2}{*}{ Economic status } & Good & 1 & & NA & NA \\
\hline & Low & $\begin{array}{l}0.55(0.20- \\
1.55)\end{array}$ & 0.258 & & \\
\hline $\begin{array}{l}\text { Level of education of parents } \\
\text { or guardian }\end{array}$ & $\begin{array}{l}\text { Tertiary } \\
\text { education }\end{array}$ & 1 & & NA & NA \\
\hline
\end{tabular}

Note: $\mathrm{OR}=$ odd ratio, $\mathrm{Cl}=$ confidence interval, $\mathrm{AOR}=$ adjusted odd ratio, $\mathrm{PSAC}=$ preschool aged children and NA = not applicable. 


\begin{tabular}{|c|c|c|c|c|c|}
\hline \multirow[t]{2}{*}{ Variable } & \multirow[t]{2}{*}{ Categories } & \multicolumn{2}{|c|}{$\begin{array}{l}\text { Univariate logistic } \\
\text { regression }\end{array}$} & \multicolumn{2}{|c|}{$\begin{array}{l}\text { Multivariate logistic } \\
\text { regression }\end{array}$} \\
\hline & & OR $(95 \% \mathrm{Cl})$ & $\begin{array}{l}\mathrm{P}- \\
\text { value }\end{array}$ & $\begin{array}{l}\text { AOR }(95 \% \\
\mathrm{Cl})\end{array}$ & $\begin{array}{l}\mathrm{P} \text { - } \\
\text { value }\end{array}$ \\
\hline & $\begin{array}{l}\text { Secondary } \\
\text { education }\end{array}$ & $\begin{array}{l}1.40(0.15- \\
13.13)\end{array}$ & 0.770 & & \\
\hline & $\begin{array}{l}\text { Primary } \\
\text { education }\end{array}$ & $\begin{array}{l}0.83(0.10- \\
6.64)\end{array}$ & 0.857 & & \\
\hline & $\begin{array}{l}\text { Never attended } \\
\text { school }\end{array}$ & $\begin{array}{l}0.66(0.07- \\
6.65)\end{array}$ & 0.724 & & \\
\hline \multirow[t]{3}{*}{ Households' population } & $11+$ & 1 & & 1 & \\
\hline & $6-10$ & $\begin{array}{l}0.09(0.02- \\
0.42)\end{array}$ & 0.002 & $\begin{array}{l}0.10(0.02- \\
0.57)\end{array}$ & 0.010 \\
\hline & $1-5$ & $\begin{array}{l}0.13(0.03- \\
0.54)\end{array}$ & 0.005 & $\begin{array}{l}0.15(0.03- \\
0.72)\end{array}$ & 0.018 \\
\hline \multirow{6}{*}{$\begin{array}{l}\text { Source of water for domestic } \\
\text { activities }\end{array}$} & Spring & 1 & & 1 & \\
\hline & Unprotected well & 0.000 & 0.998 & 0.000 & 0.998 \\
\hline & Protected well & $\begin{array}{l}0.038 \\
(0.001-1.2)\end{array}$ & 0.062 & $\begin{array}{l}0.006 \\
(0.000-0.5)\end{array}$ & 0.023 \\
\hline & $\begin{array}{l}\text { Tube well/bore } \\
\text { hole }\end{array}$ & $\begin{array}{l}0.040 \\
(0.002-0.7)\end{array}$ & 0.028 & $\begin{array}{l}0.006 \\
(0.000-0.3)\end{array}$ & 0.012 \\
\hline & $\begin{array}{l}\text { Tape away of } \\
\text { home }\end{array}$ & $\begin{array}{l}0.042 \\
(0.002-0.7)\end{array}$ & 0.029 & $\begin{array}{l}0.009 \\
(0.000-0.5)\end{array}$ & 0.020 \\
\hline & Tape at home & $\begin{array}{l}0.025 \\
(0.001-0.8)\end{array}$ & 0.034 & $\begin{array}{l}0.004 \\
(0.000-0.3)\end{array}$ & 0.015 \\
\hline \multirow[t]{2}{*}{ Nails of PSAC } & Trimmed & 1 & & NA & NA \\
\hline & Untrimmed & $\begin{array}{l}0.75(0.17- \\
3.32)\end{array}$ & 0.707 & & \\
\hline \multirow[t]{2}{*}{ Latrine availability } & Available & 1 & & NA & NA \\
\hline & Not available & $\begin{array}{l}4.57(0.95- \\
21.92)\end{array}$ & 0.058 & & \\
\hline \multirow[t]{2}{*}{ Latrine use by PSAC } & Not use & 1 & & 1 & \\
\hline & Use & $\begin{array}{l}6.89(1.99- \\
23.79)\end{array}$ & 0.002 & $\begin{array}{l}3.12(0.52- \\
18.56)\end{array}$ & 0.214 \\
\hline
\end{tabular}




\section{Discussion}

Findings of this study indicated that overall prevalence of intestinal protozoa is low among PSAC children in Mkuranga district. The overall intestinal protozoa prevalence in this study is lower compared to the prevalence recorded on PSAC in Dar es Salaam, a region located few kilometers from Mkuranga district (12). However, the prevalence reported in Dar es Salaam was based on PSAC already with symptoms of intestinal protozoa infection (diarrhea) unlike asymptomatic PSAC recruited in our study. The prevalence of non-pathogenic intestinal protozoa (Entamoeba coli) was high compared to that of pathogenic intestinal protozoa (Giardia lamblia). Similar results were found in a study conducted on school-going children in Zanzibar whereby non-pathogenic intestinal protozoa were predominantly found compared to the pathogenic one (11). The predominance of non-pathogenic intestinal protozoa was most likely because parents or guardians of infected children did not seek treatment as the children were asymptomatic. The presence of non-pathogenic intestinal protozoa is an indicator of poor sanitary and hygienic condition in a studied community (19).

Infection with intestinal protozoa were reported to be associated with several factors such as sociodemographic characteristics, economic status, place of residence, water source for domestic activities, personal hygiene and sanitation conditions $(6,20-22)$. In the current study 13 variables describing the above mentioned risk factors were assessed for their contribution on the prevalence of intestinal protozoa (Tables 1 and 2). The risk of intestinal protozoa infection was observed to significantly increase with an increase in the age of preschool children. None of the young children ( $\leq 2$ years) was infected while older PSAC ( $\geq 3$ years) had a prevalence of $5 \%$. This complies with the results obtained from studies conducted in Ethiopia whereby intestinal parasitic infections (including protozoa) were found to increase with age of the PSAC $(23,24)$. The reason could be due to the fact that, parents/guardians are less concerned with older children compared to young children. PSAC raised by older parents/guardians (above 50 years) were significantly infected than those raised by parents/guardians in other age groups. This adheres to the hypothesis that older mothers/parents/guardians are less concerned with the health of their children compared to young mothers/parents/guardians (25). This is because the majority of older mothers/parents/guardians have many children hence it is difficult for them to take care of each child. Additionally, older parents are more experienced compared to those in low age groups. Therefore, they are not serious with issues of hygienic care compared to the younger ones with low experience. Increase in number of household members was seen to increase the risk of intestinal protozoa infection which is similar to the findings from a study conducted in Ethiopia (26). The higher risk of intestinal protozoa in households with a large number of family members possibly was attributed to the fact that health-seeking behaviors in large-sized families are low compared to small-sized families (25). The decreased in health-seeking behaviors in large-sized families could be due to limited available resources which should be invested in all family members.

In the two study communities, water availability and latrine coverage were very high. A total of six water sources were reported by study participants. Moreover, about half of the PSAC population was observed to utilize latrines during defecation (Table 1). However, both water sources and latrine utilization were 
significantly associated with the prevalence of intestinal protozoa. The PSAC who reported to use spring water had a significantly high prevalence of intestinal protozoa than those reported to use piped water. Majority of PSAC parents/guardians declared that they didn't treat water for drinking (Table 1). This behavior increases the chance of intestinal protozoa transmission especially if the sources of water are not safe. The similar results were found in a study conducted in Iran (27). We expected that PSAC who utilized latrines for defecation to be less infected with intestinal protozoa than those not using (attempt open defecation). But our findings showed that the PSAC using latrine was significantly affected by intestinal protozoa than those not using the latrine. The possible reason for this could be that, PSAC who used latrines were not supervised by their parents/guardians during the process and therefore didn't adhere to the hygienic practices such as proper handwashing after latrine use and anal cleansing. Latrine use and care by themselves (PSAC) was associated with high intestinal parasitic infection (including protozoa) elsewhere (23). In addition, more than $90 \%$ of latrines in the two studied communities were not incorporated with handwashing facilities that have water and soap either inside or outside of the latrine. The presence of handwashing facilities surrounding the toilets influences the behavior of hand washing. Moreover, it is difficult for PSAC to find water and soap for washing their hands if it is not located nearby.

\section{Conclusion And Recommendation}

The results of this study show that the prevalence of intestinal protozoa among PSAC is low. Despite the low prevalence, it's clear indication that the transmission is ongoing. Water availability and latrine coverage is not a problem in the two studied communities and they are not associated with intestinal protozoa prevalence. The main possible factors which were associated with intestinal protozoa infection were the quality of water (water sources and treatment) and hygienic latrine usage. Therefore, health education on the transmission of intestinal protozoa is required among the parents/guardians of PSAC in the two communities. The health education package should include how to assist children during latrine use, water treatment for drinking and introduction of handwashing facility after defection.

\section{Abbreviations}

AOR - adjusted odd ratio

OR - odd ratio

PSAC - preschool aged children

WHO - The world health organization

\section{Declarations}

\section{Ethics approval and consent to participate}


Ethical clearance was approved by Muhimbili University of Allied and Health Sciences Ethical Review Board. Permission was sought from all government administrative level (regional to village level). Informed written consent was obtained from children parents/guardians after clarifying the aim of the study. The respondents have the right to respond fully or partially to the questionnaire. All data given by the respondents were kept confidential and used for research purposes only and confidentiality was maintained by omitting the name of the respondents.

\section{Consent for publication}

Not applicable

\section{Availability of data and materials}

All data generated or analyzed during this study are included in this published article

\section{Competing interests}

The authors declare that they have no competing interests

\section{Funding}

This work was funded by Mwalimu Julius Nyerere memorial scholarship fund (Bank of Tanzania). The fund covered expenses for sample collection and laboratory analysis. The authors declare that no other financial support was secured from other sources for this research work.

\section{Authors' contributions}

UM designed the study and collected data, UM and AZ performed laboratory analysis, AZ and VM performed statistical analysis, AZ and VM wrote the manuscript. All authors read and approved the final manuscript.

\section{Acknowledgements}

The authors wish to thank Mr. Badi. H. Badi, Mr. Rajab Mnyangema, and Ms Mary Joseph for their assistance in data collection and sample processing. Special thanks go to Ward and Village leaders and our respondents.

\section{References}


1. Ayalew A, Debebe T, Worku A. Prevalence and risk factors of intestinal parasites among Delgi school children, North Gondar, Ethiopia. J Parasitol Vector Biol. 2011;3(5):75-81.

2. Hotez PJ, Alvarado M, Basáñez M-G, Bolliger I, Bourne R, Boussinesq $M$, et al. The global burden of disease study 2010: Interpretation and implications for the neglected tropical diseases. PLoS Negl Trop Dis. 2014;8(7):e2865.

3. Hotez PJ, Fenwick A, Savioli L, Molyneux DH. Rescuing the bottom billion through control of neglected tropical diseases. Lancet. 2009;373:1570-5.

4. Sitotaw B, Mekuriaw H, Damtie D. Prevalence of intestinal parasitic infections and associated risk factors among Jawi primary school children, Jawi town, north-west Ethiopia. BMC Infect Dis. 2019;19(341):1-10.

5. Tulu B, Taye S, Amsalu E. Prevalence and its associated risk factors of intestinal parasitic infections among Yadot primary school children of South Eastern Ethiopia: a cross-sectional study. BMC Res Notes. 2014;7(848):1-7.

6. Galgamuwa L, Iddawela D, Dharmaratne S. Intestinal protozoa infections, associated risk factors and clinical features among children in a low-income tea plantation community in Sri Lanka. Int $\mathrm{J}$ Community Med Public Heal. 2016;3(9):2452-8.

7. Kirk MD, Pires SM, Black RE, Caipo M, Crump JA, Devleesschauwer B, et al. World health organization estimates of the global and regional disease burden of 22 foodborne bacterial, protozoal, and viral diseases, 2010: A data synthesis. PLoS Med. 2015;12(12):1-21.

8. Lozano R, Naghavi M, Foreman K, Lim S, Shibuya K, Aboyans V, et al. Global and regional mortality from 235 causes of death for 20 age groups in 1990 and 2010: A systematic analysis for the Global Burden of Disease Study 2010. Lancet. 2012;380(9859):2095-128.

9. Shirley DT, Farr L, Watanabe K, Moonah S. A review of the global burden, new diagnostics, and current therapeutics for amebiasis. Open Forum Infect Dis. 2018;5(7):1-9.

10. Walana W, Crowther S, Tay K, Tetteh P, Ziem JB. Prevalence of intestinal protozoan infestation among primary school children in urban and peri-urban communities in Kumasi, Ghana. Sci J Public Heal. 2014;2(2):52-7.

11. Speich B, Marti H, Ame SM, Ali SM, Bogoch II, Utzinger J, et al. Prevalence of intestinal protozoa infection among school-aged children on Pemba island, Tanzania, and effect of single-dose albendazole, nitazoxanide and albendazole-nitazoxanide. Parasit Vectors. 2013;6(1):3.

12. Ngosso BE, Nkwengulila G, Namkinga LA. Identification of pathogenic intestinal parasitic protozoa associated with diarrhea among under-fives children in Dar es Salaam, Tanzania. Int Invent J Med Med Sci. 2015;2(4):49-55.

13. United Republic of Tanzania. 2012 population and housing census population distribution by administrative areas. National Bureau of Statistics, Ministry of Finance. 2013.

14. Kakulu RK. Diarrhoea among underfive children and household water treatment and safe storage factors in Mkuranga district. Muhimbili University of Health and Allied Sciences; 2012. 
15. Google. Google map [Internet]. 2020 [cited 2020 Jun 28]. Available from: https://www.google.com/maps/dir///@-6.883992,39.1088331,11z

16. Bench aids for diagnosis of intestinal parasites. second edi. Geneve: World Health Organization; 2019.

17. MoHCDGEC. Tanzania demographic and health survey and malaria indicator survey 2015-2016. Dar es Salaam, Tanzania; 2015.

18. WHO/UNICEF. Core questions on drinking-water and sanitation for household surveys. World Health Organization. Geneva - Switzerland: WHO/UNICEF; 2006. p. 25.

19. Issa R. Non-pathogenic protozoa (Review article). Int J Pharm Pharm Sci. 2014;6(3):30-10.

20. Basualdo JA, Córdoba MA, De Luca MM, Ciarmela ML, Pezzani BC, Grenovero MS, et al. Intestinal parasitoses and environmental factors in a rural population of Argentina, 2002-2003. Rev Inst Med Trop Sao Paulo. 2007;49(4):251-5.

21. Gamboa MI, Basualdo JA, Córdoba MA, Pezzani BC, Minvielle MC, Lahitte HB. Distribution of intestinal parasitoses in relation to environmental and sociocultural parameters in La Plata, Argentina. J Helminthol. 2003;77(1):15-20.

22. Bahmani P, Maleki A, Sadeghi S, Shahmoradi B, Ghahremani E. Prevalence of intestinal protozoa infections and associated risk factors among schoolchildren in Sanandaj City, Iran. Iran J Parasitol. 2017;12(1):108-16.

23. Gadisa E, Jote K. Prevalence and factors associated with intestinal parasitic infection among underfive children in and around Haro Dumal Town, Bale Zone, Ethiopia. BMC Pediatr. 2019;19(1):1-8.

24. Aleka Y, G/egziabher S, Tamir W, Birhane M, Alemu A. Prevalence and associated risk factors of intestinal parasitic infection among under five children in University of Gondar hospital, Gondar, Northwest Ethiopia. Biomed Res Ther. 2015;2(8):347-53.

25. Uggla C, Mace R. Parental investment in child health in sub-Saharan Africa: a cross-national study of health-seeking behaviour. R Soc Open Sci. 2016;3(150460):1-13.

26. Gizaw Z, Addisu A, Gebrehwot M. Socioeconomic predictors of intestinal parasitic infections among under-five children in rural Dembiya, Northwest Ethiopia: a community-based cross-sectional study. Enviromental Heal Insights. 2019;13:1-6.

27. Abbaszadeh Afshar MJ, Barkhori Mehni M, Rezaeian M, Mohebali M, Baigi V, Amiri S, et al. Prevalence and associated risk factors of human intestinal parasitic infections: a population-based study in the southeast of Kerman province, southeastern Iran. BMC Infect Dis. 2020;20(1):1-8.

\section{Figures}




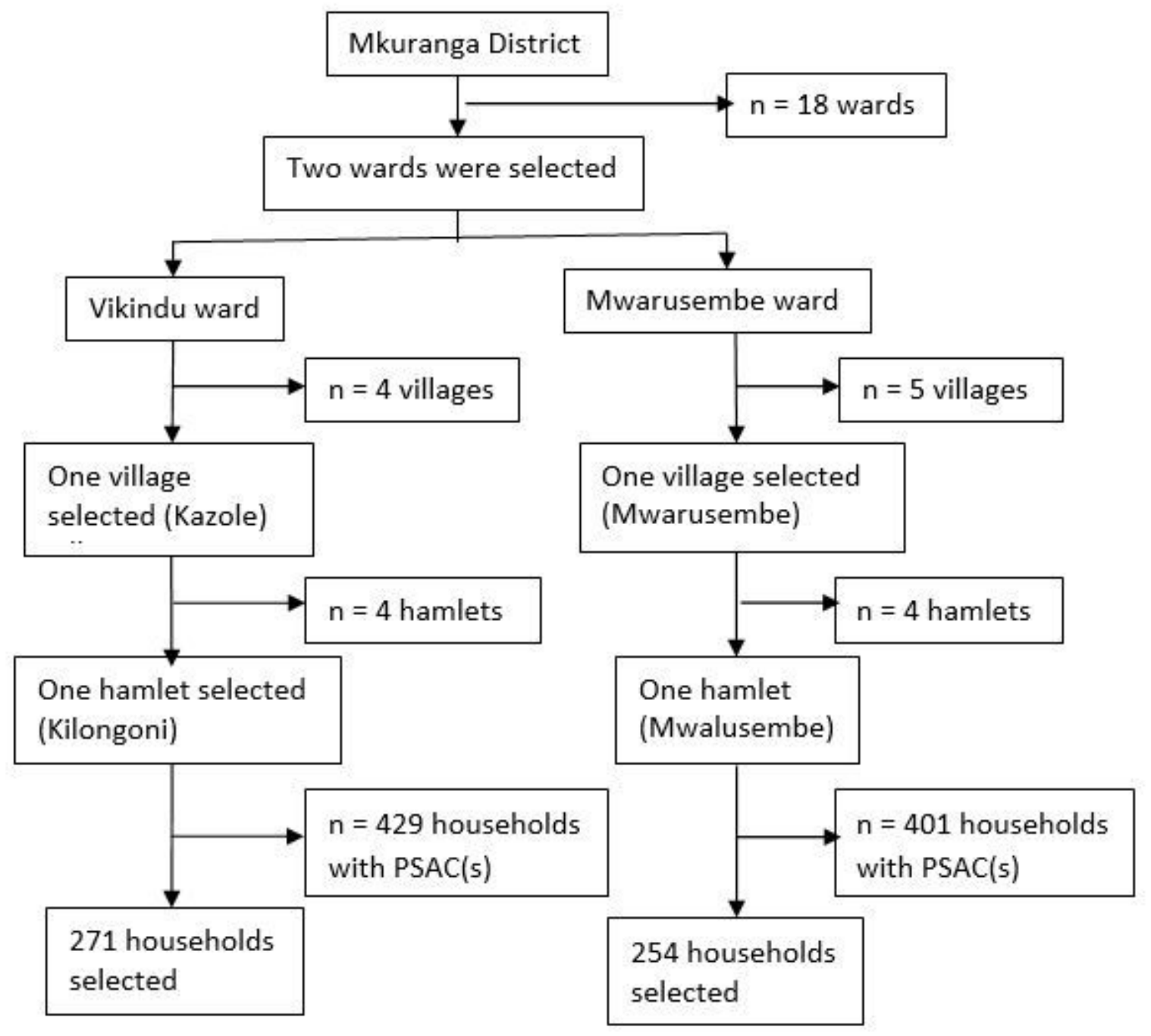

Figure 1

Flow chart showing sampling stages 